\title{
Revisional Techniques for Secondary Cleft Lip Deformities
}

\author{
Shayan M. Sarrami, BS ${ }^{1,2}$ Anna J. Skochdopole, MD ${ }^{1}$ Andrew M. Ferry, BS ${ }^{1,2}$ \\ Edward P. Buchanan, MD ${ }^{1,2}$ Larry H. Hollier Jr, MD ${ }^{1,2}$ Robert F. Dempsey, MD ${ }^{1,2}$
}

${ }^{1}$ Division of Plastic Surgery, Michael E. DeBakey Department of Surgery, Baylor College of Medicine, Houston, Texas

2 Division of Plastic Surgery, Department of Surgery, Texas Children's Hospital, Houston, Texas
Address for correspondence Robert F. Dempsey, MD, Division of Plastic Surgery, Michael E. DeBakey Department of Surgery, Baylor College of Medicine, 6701 Fannin St, Suite 610, Houston, TX 77030 (email: robert.dempsey@bcm.edu).

\begin{abstract}
Keywords

- plastic surgery

- cleft lip

- surgical revision

- pediatrics

Secondary deformities of repaired cleft lips are an unfortunate complication despite the meticulous approach of modern primary procedures. Most of these surgeries take place in the patient's early life and must be strategically planned to provide optimal cosmesis with minimal interventions. Depending on the level of severity, treatment of the secondary deformities ranges from noninvasive or minimally invasive techniques to complete revision cheiloplasty. Many novel topical, injectable, and laser therapies have allotted physicians more technical flexibility in treating superficial distortions. Nonetheless, surgical techniques such as diamond excision and adjacent tissue transfer remain popular and useful reconstructive modalities. Deformities involving the orbicularis oris must be completely taken down to allow full access to the muscle. Complete revision cheiloplasty requires recreation of the cleft defect and reconstruction similar to the primary repair. Due to the myriad of presentations of these secondary deformities, familiarity with the various treatments available is imperative for any cleft surgeon.
\end{abstract}

Congenital cleft lip is a common deformity requiring treatment from a well-experienced multidisciplinary team. The primary procedures popularized by Millard and Mulliken for unilateral and bilateral cleft lips, respectively, have been highly studied and ameliorated to achieve significantly better results., Fisher's subunit repair, Millard's rotation advancement, and the multiple modifications of these procedures have become well regarded with improved cosmesis compared with previous historical approaches. These primary procedures regularly take place in infancy between 3 and 6 months of age. ${ }^{2}$ Although a well-practiced procedure, secondary deformities are still an unfortunate commonality. ${ }^{1,3}$ Defects vary from unwanted hypertrophic scars to improper muscle function. ${ }^{4,5}$ To minimize the interventions needed, it is necessary to consider all secondary treatment options early on. ${ }^{3}$ Correcting these defects offers improved confidence, self-esteem, and peer interactions for the patient. ${ }^{6}$ Reconstructive options for the treatment of secondary cleft lip deformities are discussed in the following.

\section{Preoperative Assessment and Timing}

Both the psychosocial development of the patient and the functionality of the lip must be considered when deciding optimal timing for cleft lip revision. ${ }^{3}$ Most lip revision surgeries take place at the preschool age of around 4 to 5 years old. ${ }^{1,3,7}$ At this time, peer interactions begin to form and children become increasingly vulnerable to criticisms. ${ }^{3}$ Some centers advocate deferring revision if muscle repair is required until near completion of facial growth, which also allows the child to more proactively participate in the decision making of the revision process. ${ }^{5,8}$ However, this needs to be balanced with the patient and family's desire for earlier intervention, and is not the common practice at our
Issue Theme Revision Plastic Surgery; Guest Editor: Robert F. Dempsey, MD, FACS, FAAP (c) 2021. Thieme. All rights reserved. Thieme Medical Publishers, Inc., 333 Seventh Avenue, 18th Floor, New York, NY 10001, USA
DOI https://doi.org/ 10.1055/s-0041-1728673. ISSN 1535-2188. 
center. Nonetheless, if this approach is used, indicated orthognathic surgery should be performed prior to softtissue revision, which can significantly change the underlying bony support and thus perceived distortion of the overlying soft tissues of the lip. ${ }^{3}$

A standardized method for classifying cleft lip deformities in a meaningful way has yet to be widely agreed upon. Our center defines each defect by its involvement of superficial or muscular structures, which works well in guiding revision management. Superficial deformities are largely aesthetic and include only the skin, superficial dry mucosa, and subcutaneous tissue. ${ }^{9}$ Muscle deformities present with functional disabilities and distortion of the lip with animation. ${ }^{7,9}$ While superficial defects can be resolved via a multitude of treatment options, muscular deformities often require recreation of the defect and reconstruction similar to the primary repair., $3,7,9$

\section{Superficial Defects}

\section{Hypertrophic Scars}

Hypertrophic scar formation is due to an abnormal healing response and is seen after cleft lip repair with some regularity. ${ }^{10}$ Tension on the wound is a large contributing factor to the unsightly lesions and is worsened by the repetitive animation of the orbicularis oris. ${ }^{10,11}$ To minimize tension during the primary surgery, meticulous layered closure techniques and wound edge eversion should be utilized, limiting strain from the underlying muscle. Otherwise, the resulting fibrosis can impair soft-tissue function and pull on the lip, creating asymmetric or whistle deformities. $^{10}$

Since the 1980s, silicone has been well established for its efficacy in scar treatment. Although still not well understood, it is proposed that silicone acts as a semiocclusive barrier that hydrates the scar. ${ }^{12}$ A meta-analysis of controlled studies conducted by O'Brien and Jones demonstrates the synthetic polymer's ability to improve hypertrophic scar color and thickness. ${ }^{13}$ The largest disadvantage of silicone therapy is that it requires strict patient compliance. The treatment must be applied for almost 24 hours a day for at least 2 to 3 months. ${ }^{12,14}$ Fortunately, silicone gel has been proven to be as effective as silicone sheets, allowing for easier and less obvious application. ${ }^{15}$ This treatment can be used proactively, especially in those prone to hypertrophic scarring. ${ }^{15}$

Botulinum toxin injections may also be utilized as a therapeutic or preventative strategy. ${ }^{12,16,17}$ In controlled prospective studies by Xiao et al and Elhefnawy, botulinum toxin injections into hypertrophic scars led to some level of scar improvement in $100 \%$ of their population. They utilized a dosage of $2.5 \mathrm{IU} / \mathrm{cm}^{3}$ for 3 months at 1-month intervals. Patients and physicians judged the scars to have better overall appearance with decreased height, erythema, induration, and itching. ${ }^{18,19}$ Chang et al also showed advantageous results in a double-blind study utilizing Botox proactively during primary cleft lip repair. They described narrower scars with significantly better visual analog scale scores when using the toxin compared with the control, but the score assessing specific scar characteristics was not significantly different. ${ }^{11}$ No studies thus far report any toxin-related complications with wound healing or paralytic muscle function. ${ }^{11,18,19}$

Intralesional steroid injections, especially triamcinolone, have become a common treatment for hypertrophic scars, but have not yet been reported in cleft patients. ${ }^{10}$ Steroids inhibit the inflammatory cascade and diminish fibroblast proliferation and collagen synthesis. ${ }^{10,12}$ They have been noted to improve tissue edema, induration/fibrosis, scar elevation, and erythema. When used on facial lesions, $0.5 \mathrm{~mL} / \mathrm{cm}^{2}$ is recommended with lidocaine to reduce injection pain in the awake patient. ${ }^{20}$ Alternatively, light sedation may be utilized during injection of infants. Hypopigmentation, epidermal or fat atrophy, telangiectasias, and ulceration are all common side effects. ${ }^{20,21}$ However, it has been reported that when combined with other treatments, such as 5-fluorouracil or cryotherapy, side effects are reduced with better cosmetic outcomes. ${ }^{10,21}$

Laser therapy has been increasingly utilized for scar revision. Unfortunately, limited studies evaluate the efficacy in cleft patients. When considering laser therapy, scar characteristics and skin type effect the type of laser and parameters used. ${ }^{20}$ In general, laser therapy is most efficacious in those with lighter skin tones but can be adjusted for those with darker complexions. ${ }^{22}$ The most common lasers used in scar revision include ablative (Er:YAG, $\mathrm{CO}_{2}$ ) and nonablative (pulsed dye laser [PDL]) lasers. The PDL laser targets hemoglobin to cause collagen disulfide bond breakage, collagen fiber reorientation, and tissue hypoxia, leading to cytokine-mediated remodeling. ${ }^{22} \mathrm{PDL}$ laser therapy has largely been used in the treatment of hypertrophic scarring. ${ }^{20}$ The $\mathrm{CO}_{2}$ and Er:YAG lasers cause deepithelialization by ablation, with water as the target chromophore. $^{22}$ All types of lasers can result in minor discomfort, erythema, and risk infection. ${ }^{20}$

Lasers have been utilized prophylactically and therapeutically for improved scar appearance in cleft lip revision. ${ }^{23-25}$ Mossaad et al and Peng et al report significant improvement utilizing prophylactic laser treatment following surgery. Mossaad et al utilized a fractional $\mathrm{CO}_{2}$ laser, while Peng et al chose dual treatment with an intense pulse light laser along with a lattice $\mathrm{CO}_{2}$ laser. ${ }^{24,25}$ Nocini et al treated cheiloplasty scars with an ablative Er:YAG laser, but only reported subjective patient satisfaction. ${ }^{23}$ Thus far, no PDL lasers have been tested in cleft patients; however, these preliminary reports of laser therapy are encouraging.

\section{Tissue Deficiency}

Cheiloplasty scars are often accompanied by lip asymmetries such as a flat upper lip, indistinct philtral columns, and vermillion border deficiency. ${ }^{26}$ Physicians have increasingly utilized fat grafting to correct these issues while also benefiting from its effects on hypertrophic scars. Adipose contains a significant amount of stem cells with therapeutic neovascularization potential, providing the ability to reduce scar tissue; it also increases pliability and creates a supportive base for future grafts. ${ }^{27-29}$ Fat grafts are preferably taken from the abdomen or lateral thigh. Generally, 1 to $3 \mathrm{~mL}$ are used on a single region and 7 to $10 \mathrm{~mL}$ are utilized if multiple regions are treated. ${ }^{26,30}$ Patients have reported great satisfaction with the 

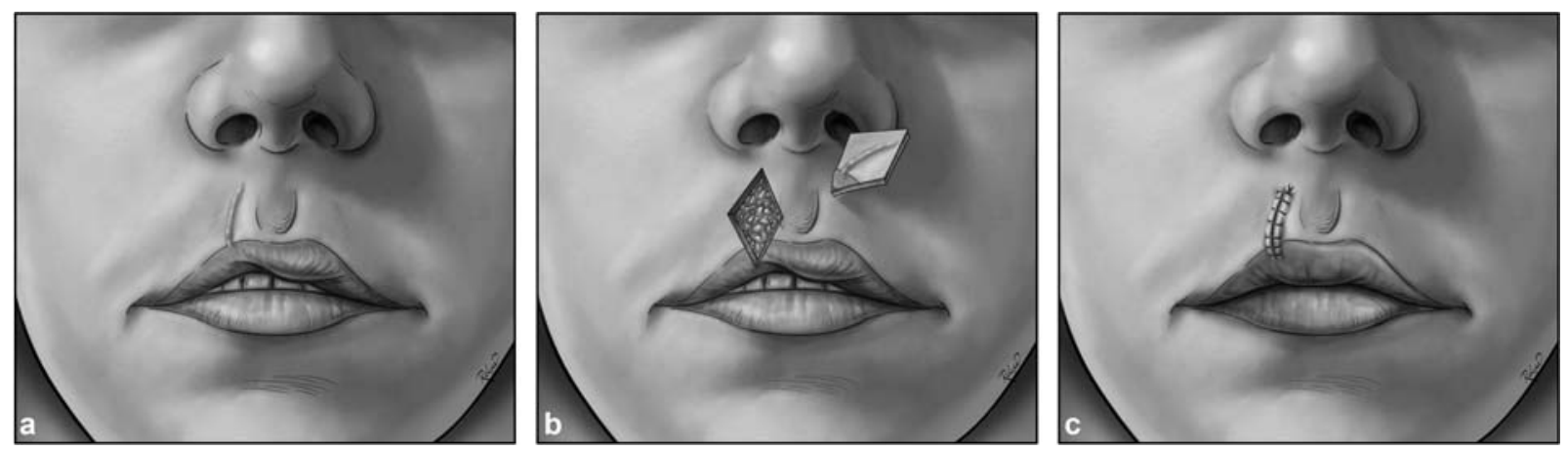

Fig. 1 Diamond excision for treatment of whistle deformity. (a) Right-sided vertical scar with secondary whistle deformity. (b) Resection of scar tissue using diamond excision. (c) Closure of wound margins with resultant correction of whistle deformity.

fullness and contour achieved through this very minor procedure. ${ }^{26,27,30}$ Due to the small volume of graft used and the vascularity of the face, these grafts have also proven to be long-lasting, giving them an added benefit over synthetic fillers. ${ }^{26,28,30}$

For treatment of older male patients with cheiloplasty scars, Akdag et al performed single-session autologous fat grafts followed by hair transplantation 3 months later. ${ }^{27,31}$ The preceding fat graft ensured a healthier tissue bed and allowed for slightly higher transplant survival. These techniques provided superb cosmetic reconstruction and coverage. $^{27}$ When utilizing hair transplants to cover cheiloplasty scars, it is important that single-hair grafts are meticulously positioned to ensure the direction of hair growth is natural. ${ }^{27,31}$

\section{Tissue Malposition}

Irregularities of the lip, mucosa, or vermillion can all be consequences of normal patient growth and wound contracture following cheiloplasty. ${ }^{3,5}$ Irregular alignment as small as $1 \mathrm{~mm}$ of the white roll or wet-dry vermilion junction is perceived as abnormal by the human eye at a conversational distance. $^{3}$ Many of these superficial irregularities can be treated with linear and diamond excisions or local flaps. ${ }^{2,5}$

Straight-line vertical excisions are rarely used but may be necessary for wide prolabium deformities or revising a wide and prominent vertical cutaneous scar., ${ }^{3,7}$ More commonly, diamond excisional procedures are used for excising scar tissue and/or scar lengthening (-Fig. 1). This procedure can be utilized in whistle deformities by pushing the vermillion inferiorly, thereby lengthening the upper lip. ${ }^{3,32}$ When possible, this procedure is used in place of Z-plasty because it offers similar results with less scar burden. However, it is limited to correction of only small defects measuring 1 to $2 \mathrm{~mm}^{3}{ }^{3}$

Z-plasty is a well-established and highly modifiable procedure. It functions to release scar contracture, reorient and lengthen scars, and redistribute tension (- Fig. 2). ${ }^{20,33}$ This technique utilizes a Z-shaped incision with the scar as the central limb. ${ }^{20}$ Once the triangular flaps are transposed, previous vertical cheiloplasty scars are lengthened and repositioned to better align with relaxed skin tension lines. ${ }^{20,34}$ Extra length can be achieved by increasing the limb and angle magnitudes or utilizing serial Z-plasties, which assure tension is evenly distributed. ${ }^{20,33} \mathrm{Z}$-plasty and its variations have been used to add length to vermillion border and short lip deformities, as well as to provide fullness and symmetry in vermillion deficiencies. ${ }^{3,34}$ Although primarily used for correction of cutaneous or mucosal defects, Z-plasty also allows access to the underlying musculature. Thus, simultaneous myoplasty may also be performed, or muscle can be included into the triangular flaps to improve durability of the result. ${ }^{34}$

$\mathrm{V}-\mathrm{Y}$ advancement, or alternatively $\mathrm{Y}-\mathrm{V}$ advancement, is a simple and effective treatment option utilized in a host of scar revision and primary closure techniques ( - Fig. 3 ). In cleft patients, it is primarily used to correct vermillion irregularities because of the large volume the flap can advance. ${ }^{3,35}$ Though most commonly utilized on the mucosal surface of the lip, it may also be designed as a full-thickness cutaneous flap to
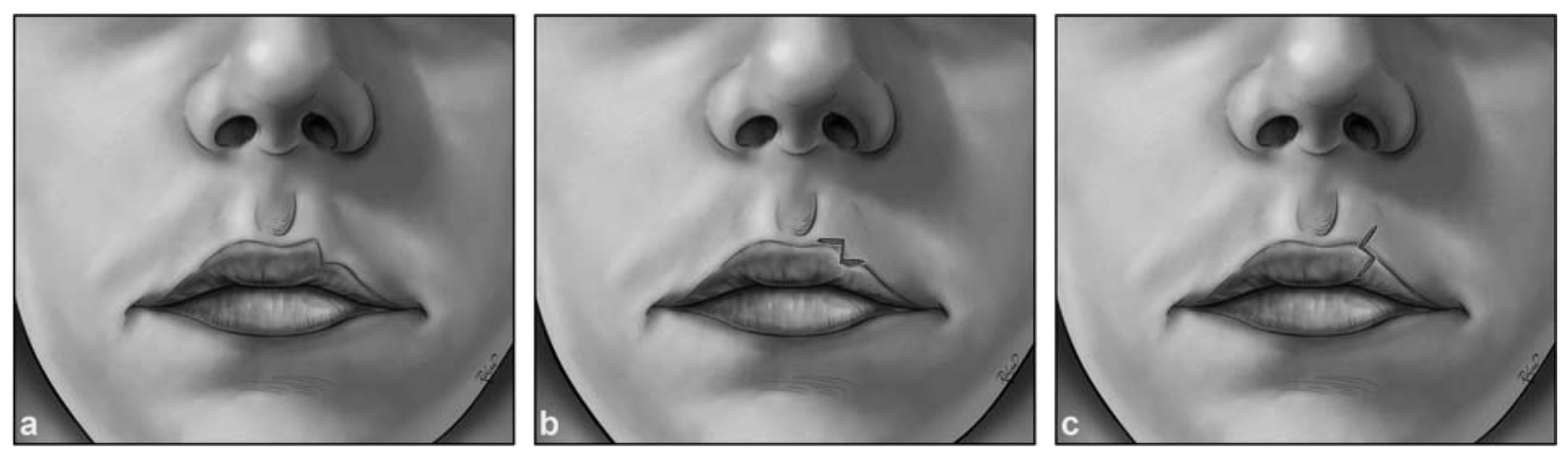

Fig. 2 Z-plasty for correction of secondary vermillion defect. (a) Left-sided vertical scar with associated vermillion and white roll defects. (b) Lip incisions are made with the vertical scar serving as the central limb of the Z-plasty design. (c) Triangular flaps are elevated, rotated, and inset to reposition and lengthen the scar for correction of the vermillion defect. 

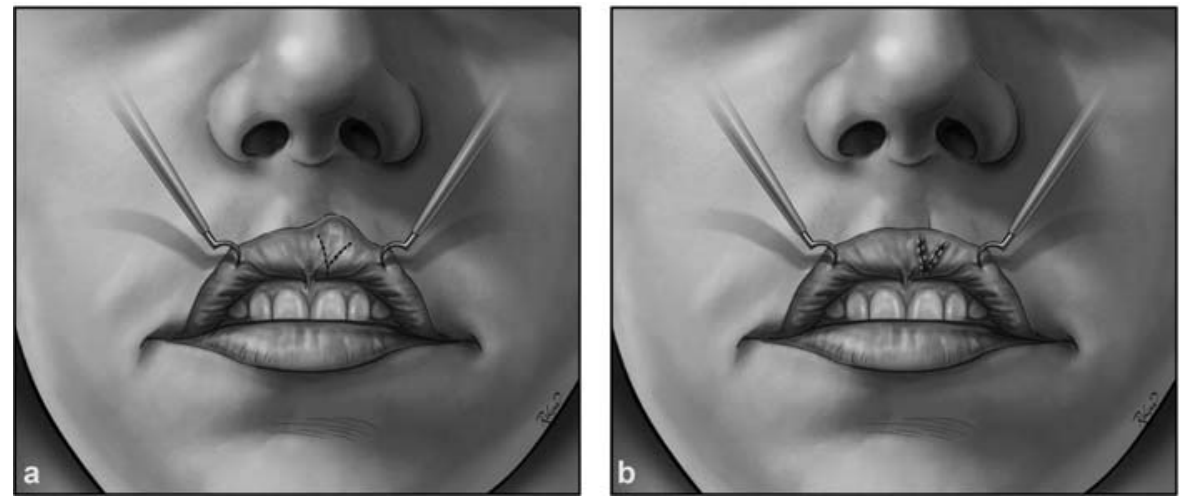

Fig. 3 (a,b) Y-V advancement of the lip mucosa for correction of vermillion excess.

include a partial-thickness incision into the muscle to ensure a strong blood supply and excursion. ${ }^{36}$ However, excessive advancement can result in lip tightening that has been described as a blooming flower or fishlike puckering. ${ }^{37}$

\section{Muscular Defects}

The orbicularis oris makes up a large portion of the upper lip volume and is associated with several secondary cleft lip distortions including wide and convex philtral and whistle deformities. ${ }^{5,7}$ Muscular impairment is best appreciated on physical exam, specifically by having the patient purse their lips. The orbicularis oris will bulge on either side if it has not been properly repaired. ${ }^{3,7}$ In these cases, complete lip revision is required to allow full access to the muscle. ${ }^{3,5,7}$ Once a full-thickness incision has been made, the orbicularis oris is isolated from the overlying skin/vermilion and from the underlying mucosa. ${ }^{38}$ The orbicularis oris and the attached nasolabial muscles are then dissected free from their abnormal attachments to the maxilla, allowing proper anatomic transverse repositioning and repair. ${ }^{5,7}$ Surgical techniques vary based on unilateral versus bilateral primary repair.

\section{Unilateral}

When secondary deformities of a unilateral cleft lip call for complete revision, Fisher's subunit repair, which incorporates a small triangular flap, is favored by the senior author
(-Fig. 4) ${ }^{5,7}$ This method minimizes the amount of scarring at the base of the nose and assures that the lateral placement of the constructed philtral column is not sacrificed for vertical lip length. ${ }^{2}$ Fisher's technique manages to hide the inevitable cheiloplasty scar along the proposed philtral ridge. ${ }^{38}$ Deficient vertical length of the medial lip element is corrected with a small back cut above the white roll into the philtral dimple. An equilateral triangular flap with limbs equal to the medial lip back cut, and not exceeding $2.5 \mathrm{~mm}$, is then designed above Noordhoff's point on the lateral lip element. The flap can then be inset into the back cut. Fisher's technique has been criticized for flattening Cupid's bow, but this may be limited with proper design and is appreciated as a normal variant in the noncleft population. ${ }^{38}$

\section{Bilateral}

Secondary bilateral cleft deformities can present with deficient central lip vermillion, inadequate gingivolabial sulcus, and a wide philtrum due to bidirectional traction of the orbicularis oris. ${ }^{2,7}$ This revision is best addressed using a modified Mulliken procedure (-Fig. 5). The procedure utilizes a philtral/ prolabium flap with converging lateral lip elements. ${ }^{39,40}$ To deepen the gingivolabial sulcus, the lateral labial mucosa and the premaxillary mucosa are utilized to form the anterior and posterior sulcus walls, respectively. ${ }^{39}$ The prolabium vermillion is commonly volume-deficient and should be discarded, while the defect is filled with lateral vermillion. ${ }^{39}$ In anticipation of
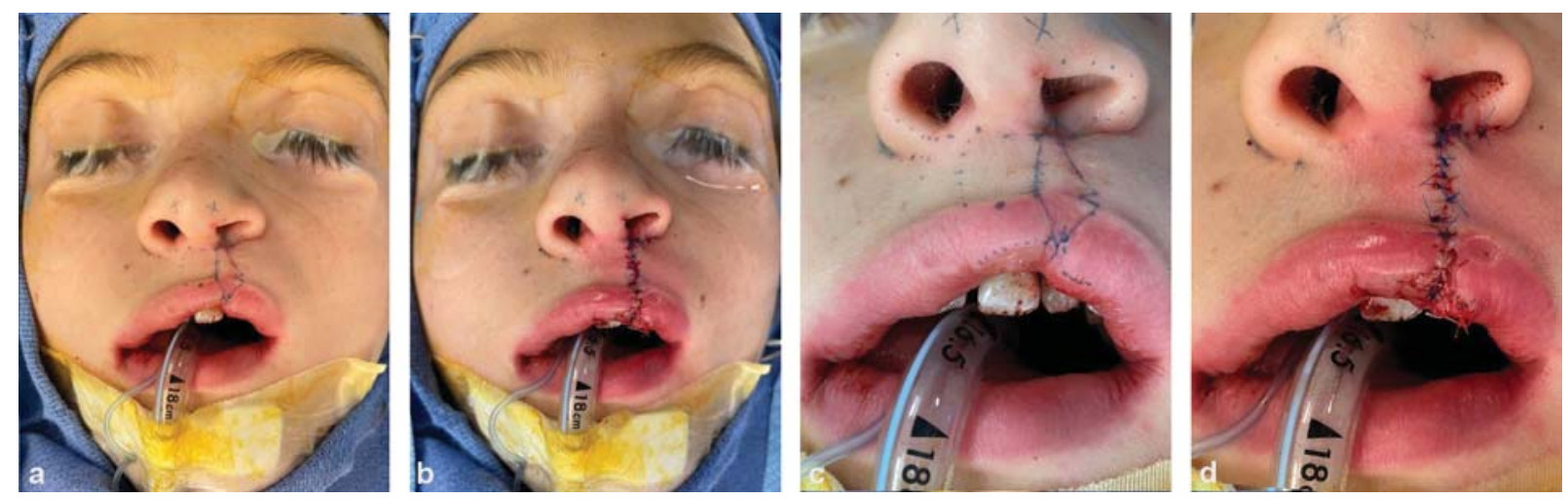

Fig. 4 Modified Fisher's unilateral cleft lip repair for correction of secondary lip deformity resulting in a short lip and white roll irregularity. Repair design from (a) anterior and (b) anterior and (c) worm's-eye views. Immediate postoperative result from (d) worm's-eye views. 

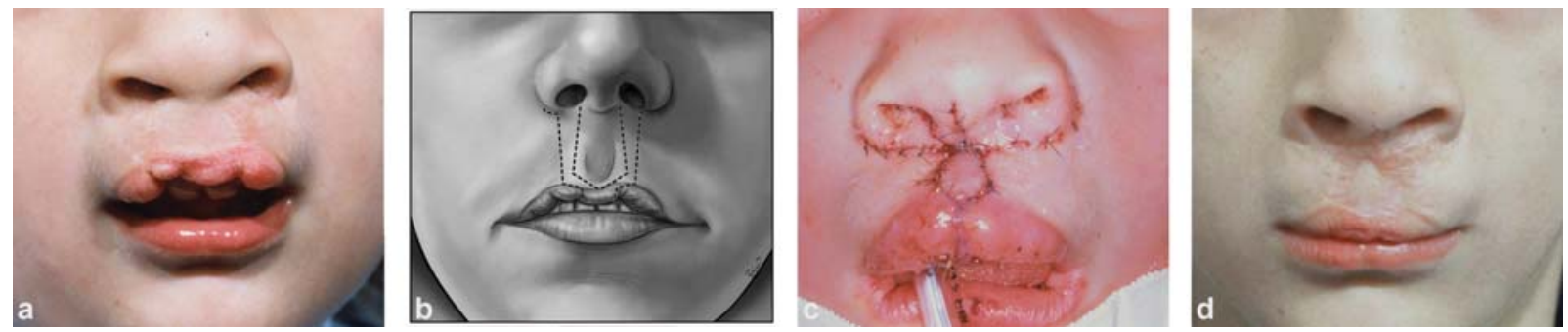

Fig. 5 Modified Mulliken's bilateral cleft lip repair for correction of secondary lip deformities. (a) Widened central lip subunit with flanking vermillion insufficiency following primary cleft lip repair. (b) Repair design. (c) Immediate postoperative result. (d) Durable postoperative result following secondary repair.

future widening, the revised philtral/prolabium flap should be designed narrower than the ultimate desired width. ${ }^{3}$ The attachment sites of the flanking flaps are used to reconstruct the philtral columns. ${ }^{41}$

In cases with extreme upper lip tightness, a protruding lower lip, and/or a very short vertical lip height, an Abbe flap may be necessary (-Fig. 6). ${ }^{7,42}$ This flap is useful for correction of both unilateral and bilateral cleft lip secondary deformities, but it is mostly employed in the latter. ${ }^{43}$ The flap is designed in the central lower lip, with a length intended to reconstruct the entire philtral unit. Its width is also designed narrower than the defect in anticipation of future widening after inset and to facilitate easier closure of the donor site. ${ }^{7,43,44}$ During flap dissection, effort should be made to preserve one side of the labial artery, which is found at the level of the white roll. However, it has been reported that ample mucosa alone $(11 \mathrm{~mm})$ can preserve the pedicled flap. ${ }^{42,43,45}$ For proper inset, continuity must be attained at the level of the skin, vermillion, muscle, and mucosa. The amount of wet vermillion used from the lower lip depends on the level of deficiency in the upper lip. ${ }^{44} \mathrm{~A}$ winged Abbe flap may be used in cases with extremely deficient vermillion. ${ }^{43}$ Neophiltral columns are reconstructed by the cutaneous scars after inset. Finally, closure of the donor site is performed in a straight-line fashion or a sublabial Z-plasty to avoid scar tethering. ${ }^{43}$
In the noncompliant patient, the cross-lip Abbe flap should be protected with temporary loose maxillomandibular fixation. ${ }^{3,7}$ Division of the pedicle can take place 2 to 3 weeks after the operation. ${ }^{43,44}$ Although this surgical technique allows for superb reconstruction of the entire upper lip, it should be mentioned that it also adds extra scar burden to the lower lip. This can be diminished by using one of the several abovementioned scar-preventing measures, and the scar frequently camouflages well in the shadow of the mental crease. ${ }^{42}$

\section{Special Considerations}

\section{Vermillion Border Asymmetry and Cupid's Bow Deformity}

Misalignment of the vermillion border is commonly due to a short vertical lip, which could be caused by scar contracture or inadequate lip lengthening upon primary repair. If the defect is within 1 to $2 \mathrm{~mm}$, diamond-shaped excisions and Z-plasties can be utilized to lengthen the deficient side. ${ }^{3,9}$ In more severe cases with a 3-mm or greater asymmetry, the lip often requires recreation of the cleft defect and redo cheiloplasty. ${ }^{3}$ Issues associated with Cupid's bow usually lie with the height and leveling of Cupid's bow peaks. Corrective procedures are largely the same as for vermillion asymmetry, though for severe deformities an Abbe flap can offer complete reconstruction. ${ }^{3}$
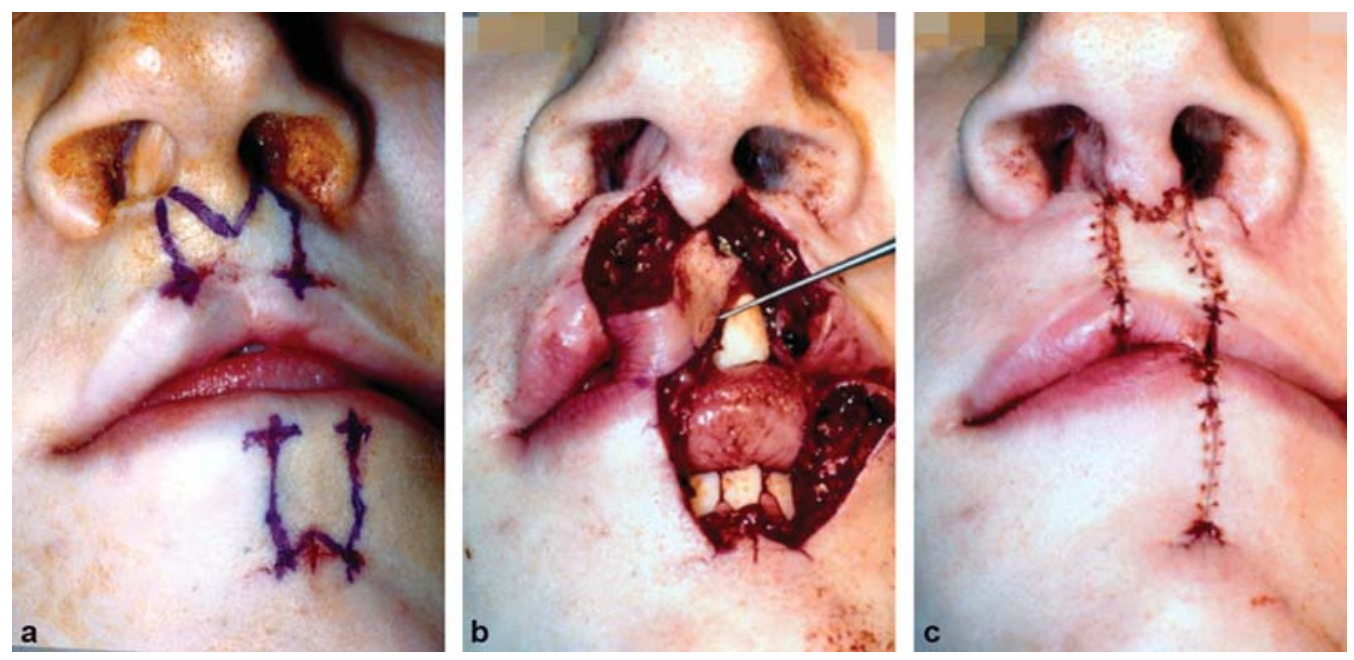

Fig. 6 Abbe flap for correction of diminutive, short central lip subunit and effacement of Cupid's bow. (a) Cupid's bow deformity with presurgical flap design. (b) Elevation and (c) subsequent inset of Abbe flap. 


\section{Philtral Column Defect}

Reconstruction of the philtral column is aided by repairing the underlying orbicularis oris muscle. ${ }^{41,46}$ Using mattress sutures to repair the muscle not only prevents muscular dehiscence, but also everts the muscle edges under the neophiltral column to augment the ridge. Other options for augmentation include dividing the muscle down the coronal plane and overlapping the four resulting muscular flaps. Additionally, securing the dermis to the underlying muscle on either side of the proposed ridge has been utilized. ${ }^{41}$ Ridge augmentation can also be achieved with autologous grafts including dermis, deepithelized scar tissue, tendon, cartilage, or muscle. Synthetic fillers are suboptimal because of their transitory effect. ${ }^{41}$ In severe cases, the Abbe flap offers the best reconstructive option. ${ }^{3}$ In this procedure, the philtral dimple can be recreated by unfurling the flap with a single subcutaneous incision or suturing to the underling muscle. However, the latter runs the risks of devitalizing the distal flap. ${ }^{41}$

\section{Mucosal Deficiency}

Sulcus deformities result in aesthetic and functional problems and make for difficult orthognathic treatment. ${ }^{7}$ Very rarely does this defect present alone. Therefore, to correct this abnormality a secondary cheiloplasty is necessary. The modified Mulliken procedure is an ideal option. ${ }^{47}$ Local flaps can also be used to enlarge the sulcus and provide ample mucosal coverage. ${ }^{9}$ Erol and Ağaoğlu present an inverted U-shaped flap taken from the mucosa of the upper lip to form the posterior wall of the sulcus. The donor site was filled with lateral mucosa. ${ }^{48}$ Alternatively, the shallow sulcus may be incised, and the defect grafted. ${ }^{3,9}$ Skin grafts may be used, but buccal mucosal grafts are preferred given their matching composition. Secondary graft contracture is a common complication and minimized with use of full-thickness grafts. Appropriate bolstering of the graft is also critical to facilitate appropriate resurfacing of the sulcus. ${ }^{3,7}$

\section{Short, Long, Tight, Wide Lip}

A lip is considered short in unilateral cleft patients when the cleft side philtral column is $3 \mathrm{~mm}$ shorter than the noncleft philtral column. ${ }^{3}$ In this case, Z-plasties are favored over diamond excision to provide adequate lengthening. ${ }^{3,9}$ In severe cases, recreation of the defect and redo cheiloplasty are often required. ${ }^{3}$ Tight lip defects are usually a bilateral cleft-associated deformity. However, both unilateral and bilateral lip tightness may be avoided with preoperative orthodontics. An Abbe flap remains the most powerful surgical tool to correct these deformities. ${ }^{3,7}$ Long lip deformities are rarely seen since they are mostly associated with Tennison repair, which is a largely historic rotational advancement procedure. Correction of these deformities requires both vertical and transverse tissue excision during revision cheiloplasty. ${ }^{3,9}$ Finally, wide lip deformities are almost exclusively seen in bilateral cleft lip patients. Treatment is achieved through vertical excision or, more commonly, redo of the modified Mulliken repair. ${ }^{3,7}$

\section{Cleft Rhinoplasty}

The material covering cleft rhinoplasty procedures is vast and outside the scope of this review. However, it should be noted that many of the above-mentioned surgical techniques can be performed concurrently with correction of secondary cleft lip nasal deformities. Mulliken's procedure for bilateral cleft lip is often paired with nasal reconstruction. ${ }^{47,49}$

\section{Conclusion}

Secondary cleft lip deformities are an undesired outcome that can be better defined by the level of the defect: superficial versus muscular. Proper recognition is critical to guide treatment. Interventions range from several noninvasive options to complete cheiloplasty redo. Familiarity with the myriad of treatments available provides surgeons with an armamentarium of options to tailor revision cheiloplasty to their patient's specific needs and subsequently produce better outcomes.

\section{Funding}

None.

Conflict of Interest

None declared.

\section{References}

1 Pai BCJ, Hung YT, Wang RSH, Lo LJ. Outcome of patients with complete unilateral cleft lip and palate: 20-year follow-up of a treatment protocol. Plast Reconstr Surg 2019;143(02):359e-367e

2 Marcus JR, Allori AC, Santiago PE. Principles of cleft lip repair: Conventions, commonalities, and controversies. Plast Reconstr Surg 2017;139(03):764e-780e

3 Stal S, Hollier L. Correction of secondary cleft lip deformities. Plast Reconstr Surg 2002;109(05):1672-1681, quiz 1682

4 Dempsey RF, Elsherbiny A, Amerson M, Sconyers L, Grant J. Normal speech should be the expected outcome in the adopted cleft child. Ann Plast Surg 2019;82(6S: Suppl 5):S370-S373

5 Garland K, Matic D. Current approaches to cleft lip revision. Curr Opin Otolaryngol Head Neck Surg 2019;27(04):287-293

6 Rothermel A, Loloi J, Long RE Jr, Samson T. Patient-centered satisfaction after secondary correction of the cleft lip and nasal defect. Cleft Palate Craniofac J 2020;57(07):895-899

7 Monson LA, Khechoyan DY, Buchanan EP, Hollier LH Jr. Secondary lip and palate surgery. Clin Plast Surg 2014;41(02):301-309

8 Ranganathan K, Shapiro D, Aliu O, et al. Health-related quality of life and the desire for revision surgery among children with cleft lip and palate. J Craniofac Surg 2016;27(07):1689-1693

9 Sittah GA, Ghanem OA, Hamdan U, Ramia P, Zgheib E. Secondary cleft nasolabial deformities: A new classification system for evaluation and surgical revision. Cleft Palate Craniofac J 2018; 55(06):837-843

10 Papathanasiou E, Trotman CA, Scott AR, Van Dyke TE. Current and emerging treatments for postsurgical cleft lip scarring: Effectiveness and mechanisms. J Dent Res 2017;96(12):1370-1377

11 Chang CS, Wallace CG, Hsiao YC, Chang CJ, Chen PKT. Botulinum toxin to improve results in cleft lip repair. Plast Reconstr Surg 2014;134(03):511-516

12 Yoo JJ, Casey LC, Herweck AM, Thaller SR. Alternative therapies to fat grafting in the craniofacial region. J Craniofac Surg 2019;30 (03):630-635

13 O'Brien L, Jones DJ. Silicone gel sheeting for preventing and treating hypertrophic and keloid scars. Cochrane Database Syst Rev 2013;2013(09):CD003826 
14 de Oliveira GV, Gold MH. Silicone sheets and new gels to treat hypertrophic scars and keloids: A short review. Dermatol Ther (Heidelb) 2020;33(04):e13705

15 Wang F, Li X, Wang X, Jiang X. Efficacy of topical silicone gel in scar management: A systematic review and meta-analysis of randomised controlled trials. Int Wound J 2020;17(03):765-773

16 Li YH, Yang J, Liu JQ et al. A randomized, placebo-controlled, double-blind, prospective clinical trial of botulinum toxin type $A$ in prevention of hypertrophic scar development in median sternotomy wound. Aesthetic Plast Surg 2018;42(05): 1364-1369

$17 \mathrm{Hu} \mathrm{L}$, Zou Y, Chang SJ, et al. Effects of botulinum toxin on improving facial surgical scars: A prospective, split-scar, double-blind, randomized controlled trial. Plast Reconstr Surg 2018; 141(03):646-650

18 Xiao Z, Zhang F, Cui Z. Treatment of hypertrophic scars with intralesional botulinum toxin type A injections: A preliminary report. Aesthetic Plast Surg 2009;33(03):409-412

19 Elhefnawy AM. Assesment of intralesional injection of botulinum toxin type A. Indian J Dermatol 2016;82(03):279-283

20 Newberry CI, Thomas JR, Cerrati EW. Facial scar improvement procedures. Facial Plast Surg 2018;34(05):448-457

21 Darougheh A, Asilian A, Shariati F. Intralesional triamcinolone alone or in combination with 5-fluorouracil for the treatment of keloid and hypertrophic scars. Clin Exp Dermatol 2009;34(02):219-223

22 Bradley DT, Park SS. Scar revision via resurfacing. Facial Plast Surg 2001;17(04):253-262

23 Nocini PF, D'Agostino A, Trevisiol L, Bertossi D. Treatment of scars with Er:YAG laser in patients with cleft lip: A preliminary report. Cleft Palate Craniofac J 2003;40(05):518-522

24 Peng L, Tang S, Li Q. Intense pulsed light and laser treatment regimen improves scar evolution after cleft lip repair surgery. J Cosmet Dermatol 2018;17(05):752-755

25 Mossaad A, Kotb A, Abdelrahaman M, Ahmady HA.surgical repair of cleft scar using fractional $\mathrm{CO}_{2}$ laser. Open Access Maced J Med Sci 2018;6(07):1231-1234

26 Shih L, Abu-Ghname A, Davis MJ, Xue AS, Dempsey RF, Buchanan EP. Applications of fat grafting in pediatric patients. Semin Plast Surg 2020;34(01):53-58

27 Akdag O, Evin N, Karamese M, Tosun Z. Camouflaging cleft lip scar using follicular unit extraction hair transplantation combined with autologous fat grafting. Plast Reconstr Surg 2018;141(01):148-151

28 Abu-Ghname A, Perdanasari AT, Reece EM. Principles and applications of fat grafting in plastic surgery. Semin Plast Surg 2019;33 (03):147-154

29 Rigotti G, Marchi A, Galiè M, et al. Clinical treatment of radiotherapy tissue damage by lipoaspirate transplant: A healing process mediated by adipose-derived adult stem cells. Plast Reconstr Surg 2007;119(05):1409-1422

30 Jones CM, Morrow BT, Albright WB, Long RE, Samson TD, Mackay DR. Structural fat grafting to improve reconstructive outcomes in secondary cleft lip deformity. Cleft Palate Craniofac J 2017;54 $(01): 70-74$
31 Miyamoto S, Takushima A, Momosawa A, Iida T, Ozaki M, Harii K. Camouflaging a cleft lip scar with single-hair transplantation using a Choi hair transplanter. Plast Reconstr Surg 2007;120(02): 517-520

32 Han K, Jeong H, Choi TH, Kim JH, Son D. Curvilinear transformation of z-shaped upper lip scar by diamond-shaped excision in secondary cleft lip deformities: A photogrammetric evaluation. Cleft Palate Craniofac J 2015;52(02):143-151

33 Ward RE, Sklar LR, Eisen DB. Surgical and noninvasive modalities for scar revision. Dermatol Clin 2019;37(03):375-386

34 Gudis DA, Patel KG. The myomucosal vertical Z-plasty in secondary cleft lip surgery: A novel technique for correction of the whistle deformity. JAMA Facial Plast Surg 2015;17(03): 215-218

35 Isken T, Sen C, Iscen D, Yildiz K. Acanthosis nigricans and an alternative for its surgical therapy. J Plast Reconstr Aesthet Surg 2009;62(01):148-150

36 Narsete TA. V-Y advancement flap in upper-lip reconstruction. Plast Reconstr Surg 2000;105(07):2464-2466. doi:10.1097| 00006534-200006000-00026

37 Baser NT, Terzioglu A, Aslan G. Reconstruction of vermilion deficiencies: The running V-flap technique. J Plast Reconstr Aesthet Surg 2012;65(10):1331-1334

38 Fisher DM. Unilateral cleft lip repair: An anatomical subunit approximation technique. Plast Reconstr Surg 2005;116(01):61-71

39 Allori AC, Marcus JR. Modern tenets for repair of bilateral cleft lip. Clin Plast Surg 2014;41(02):179-188

40 Mulliken JB. Principles and techniques of bilateral complete cleft lip repair. Plast Reconstr Surg 1985;75(04):477-487

41 Rogers CR, Meara JG, Mulliken JB. The philtrum in cleft lip: Review of anatomy and techniques for construction. J Craniofac Surg 2014;25(01):9-13

42 Lo LJ, Kane AA, Chen YR. Simultaneous reconstruction of the secondary bilateral cleft lip and nasal deformity: Abbé flap revisited. Plast Reconstr Surg 2003;112(05):1219-1227

43 Salibian AA, Zide BM. Elegance in upper lip reconstruction. Plast Reconstr Surg 2019;143(02):572-582

44 Koshy JC, Ellsworth WA, Sharabi SE, Hatef DA, Hollier LH Jr, Stal S. Bilateral cleft lip revisions: The Abbe flap. Plast Reconstr Surg 2010;126(01):221-227

45 Millard DR Jr, McLaughlin CA. Abbe flap on mucosal pedicle. Ann Plast Surg 1979;3(06):544-548

46 Naidoo S, Bütow KW. Philtrum reconstruction in unilateral cleft lip repair. Int J Oral Maxillofac Surg 2019;48(06):716-719

47 Allori AC, Mulliken JB. Evidence-based medicine: Secondary correction of cleft lip nasal deformity. Plast Reconstr Surg 2017; 140(01):166e-176e

48 Erol OO, Ağaoğlu G. Reconstruction of the superior labial sulcus in secondary bilateral cleft lip deformities: An inverted U-shaped flap. Plast Reconstr Surg 2001;108(07):1871-1873

49 Mulliken JB. Repair of bilateral complete cleft lip and nasal deformity-state of the art. Cleft Palate Craniofac J 2000;37(04): 342-347 